\title{
Can we use pulse pressure variations to predict fluid responsiveness in patients with ARDS?
}

Received: 12 March 2009

Accepted: 12 March 2009

Published online: 4 April 2009

(C) Springer-Verlag 2009

This editorial refers to the article available at:

doi:10.1007/s00134-009-1478-4.

\section{J.-Y. Lefrant}

Division of Anesthesia, Intensive Care,

Pain and Emergency Medicine,

University Hospital of Nîmes, Nimes, France

D. De Backer ( $\square)$

Department of Intensive Care, Erasme University Hospital, Université Libre de Bruxelles (ULB), Route de Lennik, 808, 1070 Brussels, Belgium

e-mail: ddebacke@ulb.ac.be

Tel.: +32-2-5553380

Fax: $+32-2-5554698$

Respiratory variations in stroke volume have been shown to be associated with preload dependency in mechanically ventilated patients without spontaneous breathing movements. Pulse pressure variations $(\triangle \mathrm{PP})$, a surrogate of stroke volume variation (SVV), predict fluid responsiveness better than static indices of cardiac preload $[1,2]$. However, SVVs and $\triangle \mathrm{PP}$ are caused by respiratoryinduced changes in preload that may be limited when patients are ventilated at low tidal volume. The reliability of $\Delta \mathrm{PP}$ could hence be theoretically limited in mechanically ventilated patients with low tidal volume [3]. An experimental study showed that changes in SVV between hemorrhage and fluid loading were limited when tidal volume was $5 \mathrm{ml} / \mathrm{kg}$ in contrast with larger changes at 10 and $15 \mathrm{ml} / \mathrm{kg}$ [4]. In mechanically ventilated acute respiratory distress syndrome (ARDS) patients, De Backer et al. [5] reported that the predictive value of $\Delta \mathrm{PP}$ for fluid responsiveness decreased when a tidal volume lower than $8 \mathrm{ml} / \mathrm{kg}$ was applied [area under the ROC (AUC ROC) $=0.71 \pm 0.09]$. A similar AUC ROC (0.768) was recently reported in 22 ARDS patients ventilated with tidal volume ranging from 5.3 to $8.3 \mathrm{ml} / \mathrm{kg}$ [6].

Unfortunately, $\Delta \mathrm{PP}$ is thus less reliable in patients with ARDS, who are often ventilated with small tidal volumes as part of protective mechanical ventilation, and these patients may particularly suffer for unjustified fluid administration. In the present issue, Vallée et al. [7] hypothesized that adjusting $\triangle \mathrm{PP}$ value for variations in alveolar pressure could be more reliable than $\Delta \mathrm{PP}$ alone in predicting fluid responsiveness. As alveolar pressure cannot be directly measured, they used changes in driving pressure $\left(\Delta \mathrm{P}=\mathrm{P}_{\text {plat }}-\mathrm{PEEP}_{\text {tot }}\right)$ as a surrogate. In 84 mechanically ventilated ICU patients, the reliability of $\Delta \mathrm{PP} / \Delta \mathrm{P}$ in predicting fluid responsiveness was better than $\triangle \mathrm{PP}(\mathrm{ROC}$ $\mathrm{AUC}=0.81$ vs. $0.71 ; P<0.01)$. In patients in whom a tidal volume $\geq 8 \mathrm{ml} / \mathrm{kg}$ was applied, the prediction of fluid responsiveness was even better $(\triangle \mathrm{PP} / \Delta \mathrm{P}$ ROC $\mathrm{AUC}=0.88$ vs. $0.75 ; P<0.01)$. However, in patients with tidal volume $<8 \mathrm{ml} / \mathrm{kg}, \Delta \mathrm{PP} / \Delta \mathrm{P}$ failed to predict fluid responsiveness (ROC AUC $=0.62$ vs. 0.72). The authors concluded that $\Delta \mathrm{PP} / \Delta \mathrm{P}$ better predicted the response to fluids than $\triangle \mathrm{PP}$ for patients ventilated with a tidal volume $\geq 8 \mathrm{ml} / \mathrm{kg}$ but failed to predict fluid responsiveness in patients ventilated at lower tidal volumes.

Why did $\Delta \mathrm{PP} / \Delta \mathrm{P}$ fail to improve the predictive value for fluid responsiveness in patients ventilated at low tidal volume? This is counterintuitive. Indeed the hypothesis for $\triangle \mathrm{PP}$ being unable to predict response to fluids at low tidal volume is that changes in pleural pericardial pressures are too low. Accordingly, correcting for a lower driving pressure should theoretically compensate for this. Several factors may explain this failure. First, driving pressure may be increased, not 
Table 1 Driving pressure calculated from airway and esophageal pressures (recalculated from mean values provided in study by Talmor et al. [10])

\begin{tabular}{lcc}
\hline & $\begin{array}{l}\text { Esophageal } \\
\text { pressure-guided } \\
\text { group }(n=30)\end{array}$ & $\begin{array}{l}\text { Conventional } \\
\text { treatment group } \\
(n=31)\end{array}$ \\
\hline Plateau pressure $\left(\mathrm{cmH}_{2} \mathrm{O}\right)$ & 29 & 29 \\
End-expiratory pressure $\left(\mathrm{cmH}_{2} \mathrm{O}\right)$ & 14 & 15 \\
Driving pressure from esophageal pressure airway pressures $(\Delta \mathrm{P})\left(\mathrm{cmH}_{2} \mathrm{O}\right)$ & 14 & 15 \\
Esophageal end-inspiratory pressure $\left(\mathrm{cmH}_{2} \mathrm{O}\right)$ & 21.2 & 20.7 \\
Esophageal end-expiratory pressure $\left(\mathrm{cmH}_{2} \mathrm{O}\right)$ & 17.2 & 16.9 \\
Driving pressure from esophageal pressure $\left(\mathrm{cmH}_{2} \mathrm{O}\right)$ & 4.0 & 3.8 \\
\hline
\end{tabular}

decreased in ARDS patients ventilated at low tidal volume. Indeed, compliance is typically decreased in ARDS patients, accordingly driving pressure should increase for a given tidal volume [8]. Indeed, Vallée et al. [7] observed that $\Delta \mathrm{P}$ was higher in patients ventilated with low tidal volume, predominantly ALI/ ARDS patients, compared to the others (19 vs. 15 $\left.\mathrm{cmH}_{2} \mathrm{O}, P<0.05\right)$. Hence, correction for $\Delta \mathrm{P}$ would further impair, not improve, the performance of $\Delta \mathrm{PP}$. Second, driving pressure may fail to reflect the changes in pleural and pericardial pressure, especially in ARDS. Indeed, the pressure transmitted from the airways to the pleural and pericardial spaces depends on physical properties of the lung. In ARDS, the amount of alveolar pressure transmitted to the pleura is decreased compared to healthy lungs. Data recalculated from Jardin et al. [9] demonstrated that the pressure transmitted to the pleural space for a given tidal volume is constant at various compliance levels [5]. From the recent study by Talmor et al. [10], we can also recalculate that driving pressure estimated from airways pressure markedly overestimates changes in pleural pressure, as estimated with esophageal balloons, in patients with ARDS (Table 1). Even though it is quite speculative, it is likely that $\Delta \mathrm{PP} / \Delta \mathrm{P}$ may be reliable in patients with normal lungs ventilated at low tidal volume: in these patients $\Delta \mathrm{P}$ would be low as compliance is high and will reflect the pressure transmitted to the pleural and pericardial spaces. It may be that only a minority of patients are implicated, as most of the patients ventilated with low tidal volume suffer from acute lung injury (ALI) or ARDS.

Another important finding from this study is that correcting $\Delta \mathrm{PP}$ for tidal volume did not result in better performance than $\Delta \mathrm{PP} / \Delta \mathrm{P}$, further illustrating that the relationship between tidal volume and changes in pleural and pericardial pressure is complex and nonlinear.

What can we do in practice to predict fluid responsiveness in patients with ARDS ventilated with tidal volumes lower than $8 \mathrm{ml} / \mathrm{kg}$ ? One consideration would be to use a lower cut-off for $\triangle \mathrm{PP}$. De Backer et al. [5] noticed that an $8 \%$ value satisfactorily identified responders and nonresponders to fluids, but we have also to consider that the lower the value the higher the chances that it may be influenced by small errors in measurements. Alternatively, one may consider using the traditional $12 \%$ cut-off value, which may be expected to have a low sensitivity but a satisfactory specificity [6]. Finally, one may consider performing a passive leg-raising test $[11,12]$.

In conclusion, the study by Vallée et al. [7] confirms that $\Delta \mathrm{PP}$ remains a clinically helpful tool to predict fluid responsiveness in patients ventilated with tidal volumes of at least $8 \mathrm{ml} / \mathrm{kg}$ but that this index has a limited value in patients ventilated at lower tidal volumes. Correction of $\Delta \mathrm{PP}$ by $\Delta \mathrm{P}$ improved the performance of the test in patients with relatively healthy lungs but not in patients with ARDS, as the transmission of airway pressure to pleural and pericardial pressure is affected in ARDS.

\section{References}

1. Michard F, Boussat S, Chemla D, Anguel N, Mercat A, Lecarpentier Y, Richard C, Pinsky MR, Teboul JL (2000) Relation between respiratory changes in arterial pulse pressure and fluid responsiveness in septic patients with acute circulatory failure. Am $\mathbf{J}$ Respir Crit Care Med 162:134-138

2. Michard F, Teboul JL (2002) Predicting fluid responsiveness in ICU patients: a critical analysis of the evidence. Chest 121:2000-2008
3. Michard F (2005) Changes in arterial pressure during mechanical ventilation. Anesthesiology 103:419-428; quiz 449-415

4. Renner J, Cavus E, Meybohm P, Tonner P, Steinfath M, Scholz J, Lutter G, Bein B (2007) Stroke volume variation during hemorrhage and after fluid loading: impact of different tidal volumes. Acta Anaesthesiol Scand 51:538-544
5. De Backer D, Heenen S, Piagnerelli M, Koch M, Vincent JL (2005) Pulse pressure variations to predict fluid responsiveness: influence of tidal volume. Intensive Care Med 31:517-523

6. Huang CC, Fu JY, Hu HC, Kao KC, Chen NH, Hsieh MJ, Tsai YH (2008) Prediction of fluid responsiveness in acute respiratory distress syndrome patients ventilated with low tidal volume and high positive end-expiratory pressure. Crit Care Med 36:2810-2816 
7. Vallée F, Richard JCM, Mari A, Gallas T, Arsac E, Verlaan PS, Chousterman B, Samii K, Genestal M, Fourcade O (2009) Pulse pressure variations adjusted by alveolar driving pressure to assess fluid responsiveness. Intensive Care Med. doi: 10.1007/s00134-009-1478-4

8. de Chazal I, Hubmayr RD (2003) Novel aspects of pulmonary mechanics in intensive care. Br J Anaesth 91:81-91
9. Jardin F, Genevray B, Brun-Ney D, Bourdarias JP (1985) Influence of lung and chest wall compliances on transmission of airway pressure to the pleural space in critically ill patients. Chest 88:653-658

10. Talmor D, Sarge T, Malhotra A, O'Donnell CR, Ritz R, Lisbon A, Novack V, Loring SH (2008) Mechanical ventilation guided by esophageal pressure in acute lung injury. N Engl J Med 359:2095-2104
11. Monnet X, Teboul JL (2008) Passive leg raising. Intensive Care Med 34:659663

12. Lamia B, Ochagavia A, Monnet X, Chemla D, Richard C, Teboul JL (2007) Echocardiographic prediction of volume responsiveness in critically ill patients with spontaneously breathing activity. Intensive Care Med 33:11251132 